\title{
Estimating sea ice coverage, draft, and velocity in Marguerite Bay (Antarctica) using a subsurface moored upward-looking acoustic Doppler current profiler (ADCP)
}

\author{
Jason Hyatt ${ }^{1,2}$, Martin Visbeck ${ }^{3}$, Robert C. Beardsley ${ }^{1}$, and W. Brechner Owens ${ }^{1}$ \\ 1 - Department of Physical Oceanography, Woods Hole Oceanographic Institution, \\ Woods Hole, MA 02543 \\ 2 - Science and Mathematics Department, Massachusetts Maritime Academy, \\ Buzzards Bay, MA 02532 email: jhyatt@maritime.edu
}

3 - Leibniz-Institut fuer Meereswissenschaften (IFM-GEOMAR), Duesternbrooker Weg 20, 24105 Kiel, Germany

September 14, 2007

\begin{abstract}
A technique for the analysis of data from a subsurface moored upward-looking acoustic Doppler current profiler (ADCP) to determine ice coverage, draft and velocity is presented and applied to data collected in Marguerite Bay on the western Antarctic Peninsula shelf. This method provides sea ice information when no dedicated upward-looking sonar (ULS) data is available. Ice detection is accomplished using windowed variances of ADCP vertical velocity, vertical error velocity, and surface horizontal speed. ADCP signal correlation and backscatter intensity were poor indicators of the presence of ice at this site. Ice draft is estimated using a combination of ADCP backscatter data, atmospheric and oceanic pressure data, and information about the thermal stratification. This estimate requires corrections to the ADCP-derived range for instrument tilt and sound speed profile. Uncertainties of $\pm 0.20 \mathrm{~m}$ during midwinter and $\pm 0.40 \mathrm{~m}$ when the base of the surface mixed layer is above the ADCP for ice draft are estimated based on (a) a Monte Carlo simulation, (b) uncertainty in the sound speed correction, and (c) performance of the zero-draft estimate during times of known open water. Ice velocity is taken as the ADCP horizontal velocity in the depth bin specified by the range estimate.
\end{abstract}

Key words: sea ice, ice draft, ice drift, ADCP, Marguerite Bay, Antarctic Peninsula 


\section{Introduction}

Upward-looking Acoustic Doppler Current Profilers (ADCPs) have been successfully deployed in the world oceans for many years on bottom-anchored subsurface moorings. The primary purpose of the ADCP has been to measure vertical profiles of ocean currents. When an upward-looking ADCP is deployed in a location that experiences seasonal sea ice cover, it can also be used to collect sea ice data (e.g. Belliveau et al., 1990; Visbeck and Fischer, 1995; Strass, 1998; Shcherbina et al., 2005). This has become more important as the effort to observe the remote polar seas has increased due to their critical roles in the global climate system.

The presence of sea ice has a strong influence on the exchange of heat and momentum between the atmosphere and the ocean. The lateral motion of sea ice moves both fresh water and heat. Furthermore, the presence of seasonal sea ice is believed to play a vital role in krill population and ecosystem dynamics throughout Antarctica (Hofmann et al., 2004). Combined in situ observations of sea ice coverage, draft and velocity provide data of great benefit to many investigations, particularly when measured at the same time and location.

Ice draft has been successfully measured with upward-looking sonars (ULS) (e.g. Hudson, 1990; Strass, 1998; Fukamachi et al., 2003). An ULS typically samples at high frequency (e.g. $0.5 \mathrm{~Hz}$ ) using one narrow vertical beam. This single beam avoids errors due to lateral scattering between multiple slanted beams that can occur with the four-beam ADCP. Unlike the ULS, ice drift velocities can be measured using an ADCP in bottom-track (BT) mode (Belliveau et al., 1990), however, the bottom-track pings require additional power which can be problematic in long-term moored deployments. Visbeck and Fischer (1995) estimated the presence of ice and drift velocity using a narrow-band ADCP in water-track (WT) mode, the mode normally used for water velocity profiling deployments, but did not estimate ice draft. Shcherbina et al. (2005) recently showed that ice draft estimates made using a bottom-mounted broad-band ADCP that recorded data in both BT and WT mode were of comparable accuracy. The combination of ULS and ADCP provides the best measurements of ice draft and motion and allows proper spatial averaging of ice properties to obtain statistical descriptions of the ice bottom topography (e.g. Melling et al., 1995; Fukamachi et al., 2003). This configuration can still have problems estimating ice draft due to errors in the estimation of range-averaged sound speed since one does not normally make in situ temperature and salinity measurements between the ULS and the sea surface/ice bottom (i.e., the sensors would block the single vertical acoustic beam). 
We describe here a method for processing WT mode ADCP data from a standard subsurface mooring (Fig. 1) to estimate ice coverage and draft that can be applied to both broad- and narrow-band ADCP data. This method provides estimates of sea ice draft in the absence of ULS data by taking advantage of auxiliary data from other instruments on the mooring. We estimate the uncertainty in the ice draft estimate, and compare this with the uncertainty in an ULS estimate. The information provided by this method, while by no means a substitute for ULS data, can improve the interpretation of the ocean current data recorded by the ADCP. The method presented here builds on Visbeck and Fischer (1995) and is similar to that developed by Shcherbina et al. (2005) to estimate ice presence and draft using a fixed bottom-mounted ADCP deployed in relatively shallow water. Both methods can be used with archived ADCP data to provide historical estimates of ice draft provided sufficient supporting data on in situ sound speed and pressure variability are available.

We use data collected from a subsurface mooring deployed in Marguerite Bay on the western Antarctic Peninsula shelf to demonstrate that the proposed method can provide useful estimates of ice draft. The basic data set is described in section 2 , followed by a detailed presentation of the proposed method applied to these data in sections 3 to 5. The final sections of this paper include recommendations for future deployments of subsurface-moored ADCPs in ice-covered regions and conclusions.

\section{Data}

The Southern Ocean Global Ocean Ecosystems Dynamics (SO GLOBEC) field program was designed to investigate the physical oceanography and marine ecosystem processes with a special emphasis on krill in Marguerite Bay and the adjacent western Antarctic Peninsula (wAP) shelf (Hofmann et al., 2004). As part of this effort, several subsurface moorings and two Automatic Weather Stations were deployed in Marguerite Bay and CTD data collected on a sequence of mooring and hydrographic cruises to the region during 2001-2003.

We focus here on data collected on the C3 mooring deployed in the mouth of Marguerite Bay (68 $06.006^{\circ}$ S, $70^{\circ} 31.799^{\prime}$ W; water depth $811 \mathrm{~m}$ ) from February 21, 2002 to February 26, 2003. A map of the study region is given in Bolmer (this issue). Deployed during the austral ice-free season, the $\mathrm{C} 3$ mooring recorded data during the formation and subsequent breakup of the seasonal sea ice before recovery the next austral summer. The upper part of the $\mathrm{C} 3$ mooring 
supported an upper-looking RDI 300-kHz broad-band ADCP at a nominal depth of $108 \mathrm{~m}$, SBE model 37 MicroCAT temperature and conductivity recorders at 99, 147, 197, 248 m, SBE model 39 temperature recorders at 122, 172, and $222 \mathrm{~m}$, and a Vector-Averaging Current Meter (VACM) equipped with a pressure sensor at $247 \mathrm{~m}$. The ADCP was setup with 2-m depth bins and 120 pings per ensemble over a 30-min period (15 sec between pings), and recorded ensemble mean $u, v, w$ currents, acoustic backscatter strength in each beam, compass heading, instrument tilt, and sensor temperature. The nominal horizontal current measurement error for this setup was $\pm 0.6 \mathrm{~cm} \mathrm{~s}^{-1}$. The SBE temperature recorders and MicroCATs recorded data at $225 \mathrm{sec}$ and $150 \mathrm{sec}$ respectively, with nominal uncertainties in the temperature and conductivity data of \pm $0.002{ }^{\circ} \mathrm{C}$ and $\pm 0.003 \mathrm{mS} \mathrm{cm}^{-1}$ (or $\pm 0.005 \mathrm{psu}$ in salinity).

The VACM strain-gauge pressure sensor (Paine 0-4400 psi) had a large full-scale range (3000 $\mathrm{db}$ ) but a relatively stable calibration and low temperature sensitivity. Measurement uncertainty due to calibration was $\pm 0.370 \mathrm{db}$. The uncertainty due to temperature variability was $\leq \pm 0.228$ $\mathrm{db}{ }^{\circ} \mathrm{C}^{-1}$, however the sensor experienced relatively little temperature variability during the deployment (mean $T$ was $1.27 \pm 0.11^{\circ} \mathrm{C}$, with a range of $0.71{ }^{\circ} \mathrm{C}$ ) so that the net measurement uncertainty due to temperature was $\pm 0.162 \mathrm{db}$. The pressure data was averaged over $7.5 \mathrm{~min}$ and recorded every $15 \mathrm{~min}$ with a resolution of $0.008 \mathrm{db}$. The $\mathrm{C} 3$ mooring used $1-\mathrm{m}$ diameter flotation spheres at depths of 101 and $247 \mathrm{~m}$ for its primary buoyancy, reducing current-induced mooring tilt to a minimum. With maximum observed currents $<13 \mathrm{~cm} \mathrm{~s}^{-1}$, the dip in ADCP and VACM pressure sensor depth should be $<0.05 \mathrm{~m}$ (S. Worrilow, pers. comm.).

Atmospheric pressure was measured by two separate Automatic Weather Stations (AWSs) deployed in Marguerite Bay in proximity to provide redundancy in case of failure and the ability to check for failure by intercomparison. The AWSs were located on small rocky islets named Kirkwood Island (68 $\left.0.397^{\prime} \mathrm{S}, 6^{\circ} 00.444^{\prime} \mathrm{W}\right)$ and Dismal Island (68 05.243' S, 68 $\left.49.480^{\prime} \mathrm{W}\right)$ separated by $29 \mathrm{~km}$, and had sensor heights of 12 and $25 \mathrm{~m}$ above mean sea level, respectively. The AWS data were transmitted via ARGOS satellite to the University of Wisconsin Antarctic Meteorological Research Center, where the 10-min data were edited and averaged to provide hourly time series with a nominal uncertainty of $\pm 0.2 \mathrm{mb}$. The Kirkwood and Dismal atmospheric pressure data agreed to within $\pm 1 \mathrm{mb}$ after adjustment for the difference in sensor height. The Kirkwood AWS was slightly closer to the $\mathrm{C} 3$ mooring $(68 \mathrm{~km})$ so its pressure data 
were used here. (See Moffat et al. (2005) for more details about the SO GLOBEC moored array and AWS component and data.)

Two methods were used to derive ice concentration time series using Special Sensor Microwave/Imager (SSM/I) data for comparison with the C3 ADCP-based ice concentration estimates. The first is based on the NASA Team (NT) algorithm (Cavalieri, et al., 1990; 2005) and the second on the bootstrap (BS) algorithm (Comiso, 1999; updated 2005). Both methods provided daily mean ice concentration with a pixel size of 25 by $25 \mathrm{~km}$. The distance between $\mathrm{C} 3$ and the closest NT and BS pixel centers was $12.2 \mathrm{~km}$.

\section{Ice Detection}

The detection of ice has been performed using ADCP BT pings (e.g. Belliveau et al., 1990; Shcherbina et al., 2005), upward-looking sonars (ULS) (Strass, 1998; Fukamachi et al., 2003), and both narrow-band and broad-band ADCP WT pings (Visbeck and Fischer, 1995; Shcherbina et al., 2005). The method described here essentially duplicates the method for a narrow-band ADCP in WT mode, with some differences noted for a broad-band ADCP.

We employ a set of criteria that discriminate, from time averages of the ADCP data, in a binary way the presence of ice. First, the ADCP bin that samples the sea surface or sea ice bottom is identified as the bin above the one with maximum backscatter intensity. This upper bin is chosen to ensure ice-only data due to overlapping cell information as a result of the range gating in an ADCP (RDI-Primer, 1996). While it is possible to use a weighted average of bins, we chose the simplest option of using only this upper bin.

Possible ice detection criteria are 1) vertical velocity variance, 2) error velocity variance, 3 ) surface backscatter intensity, 4) horizontal surface speed, and 5) surface signal correlation. Signal correlation is the only additional piece of information provided by a broad-band ADCP. These properties are all greatly influenced by the presence of sea ice (Visbeck and Fischer, 1995; Shcherbina et al., 2005). A successful criterion for the presence of sea ice is one where the variable has a strongly bimodal distribution with the two maxima in the probability distribution function significantly separated and identifiable with times when the location is ice-covered or ice-free. One then defines a "cut-off" value that delineates the boundary between the two regions. 
The top panel in Figure 2 shows a time series of the high-pass filtered error velocity that clearly reveals approximate times when ice is present. This is used to make a first approximation of when ice is present (marked in black) based on inspection of the time series and visual identification of periods of low variance. Next, cumulative histograms are made of each of the criteria to find suitable cutoff values (Fig. 2). Criteria which show a clear separation between ice and no ice are, in our case, the windowed variance of the error velocity, the squared windowed variance of vertical velocity, and the surface speed. (Unlike Visbeck and Fischer (1995) using a $150-\mathrm{kHz}$ narrowband ADCP in the Greenland Sea and Shcherbina et al. (2005) using a 300-KHz broadband ADCP bottom-mounted in the Okhotsk Sea, we did not find surface backscatter intensity and surface signal correlation as useful indicators of ice presence.) After a subjective trial and error process, we take the cutoff values to be when the cumulative histograms for the ice period reaches $90 \%$ and the open water period is less than $10 \%$. They work well to identify the best criteria for discerning ice presence in our record and for comparison with satellite-based estimates of ice coverage, as described below.

Then tagging each half hourly ADCP data point as "ice" or "no ice" makes a time series of ice presence. One can choose to simply use one of the criteria, or combine them by taking the average or cross-correlation of two or more indicators. Next, a daily average ice concentration in the area of the mooring is calculated as the percentage of "ice" measurements in one day (Visbeck and Fischer, 1995). This assumes that the ice is moving overhead in a statistically random way on daily time scales.

Finally, the time series of ice concentration can be compared with satellite-based sea ice estimates and cutoff values for criteria for ice presence can be fine tuned if necessary. For example, one might need to identify and possibly omit times of calm winds which can produce low vertical velocity variance and thus false ice detection (Visbeck and Fischer, 1995). However, in the case shown here, surface wind data collected nearby had no periods of time where winds were light enough for a long enough period of time (less than $5 \mathrm{~m} \mathrm{~s}^{-1}$ for more than 2 days) to warrant this extra step.

The C3 ADCP-derived ice concentration time series is compared in Fig. 3 (top panel) with SSM/I-based time series computed using the NASA Team (NT) and bootstrap (BS) algorithms. The ADCP time series is an average of three time series which were computed using as cutoff criteria windowed variance of error velocity $\left(0.0006 \mathrm{~cm}^{2} \mathrm{~s}^{-2}\right)$, the squared windowed variance of 
vertical velocity $\left(0.4 \mathrm{~cm}^{4} \mathrm{~s}^{-4}\right)$, and the surface speed $\left(26.5 \mathrm{~cm} \mathrm{~s}^{-1}\right)$. In general, the three time series exhibit similar behavior, e.g. rapid onset of ice cover in mid-May to concentrations $\geq 90 \%$ in June, then significant variability through austral winter, a period of more open conditions in mid-October through November, and finally the return of open water by January. The ADCP time series exhibits the most day-to-day variability, while the BS estimates generally exceed the NT estimates. As noted by Stammerjohn and Smith (1996) for SSM/I data from the western Antarctic Peninsula shelf region, NT estimates are biased low at the higher concentrations, e.g. the average NT value is $87 \%$ for a group with an average BS value of $96 \%$ (Fig. 3 center left panel). This bias is also observed at the lower concentrations, where there are fewer BS values below $\mathrm{BS}=15 \%$ than NT values. Within the large scatter shown between individual ADCP and BS values, the bin-averaged ADCP and BS mean values (Fig. 3 center right panel) show reasonable agreement for ice concentrations above $60 \%$.

The ADCP time series exhibits larger variability than both SSM/I time series, due in part to the large different in spatial averaging between the ADCP and satellite data. The nominal pixel size of both NT and BS data is 25 by $25 \mathrm{~km}$, making a footprint area of $625 \mathrm{~km}^{2}$. For the C3 $\mathrm{ADCP}$ at a depth of $108 \mathrm{~m}$, with $\theta=20^{\circ}$ and beamwidth $\varphi=3.8^{\circ}$ at $-3 \mathrm{~dB}$ (Fig. 1; RDI-Primer, 1996; R. Hippe, pers. comm.), the four ADCP beams have a combined surface footprint area of $49 \mathrm{~m}^{2}$. The area sampled by the ADCP during a 24-hr period is the total width of the beams (16 $\mathrm{m})$ times the distance the ice has traveled over the instrument during that period. At $\mathrm{C} 3$, the average distance traveled by ice in a day is $1.1 \mathrm{~km}$ (with $95 \%$ of the values less than $28 \mathrm{~km}$ ), thus giving an average daily footprint of $17,600 \mathrm{~m}^{2}$, four orders of magnitude smaller than the satellite footprint. Thus, the ADCP can be sampling leads and small areas of open water, which might not impact significantly the ice concentration averaged over the larger satellite pixel. See Melling et al. (1995) for detailed treatment of spatial and temporal averaging of ice data collected using moored platforms.

\section{Ice Draft}

Ice draft $h_{\text {ice }}$ is defined as the depth of ice below waterline (Fig. 1). Here we estimate $h_{\text {ice }}$ as the difference between the ADCP depth $h_{o}$ and the vertical distance $h_{l}$ to the underside of the ice:

$$
h_{\text {ice }}=h_{o}-h_{l}
$$

The ADCP depth $h_{o}$ is computed using the hydrostatic pressure balance as 


$$
h_{o}=\frac{P_{o}-P_{\text {air }}}{\bar{\rho} g}-h_{2}
$$

where $P_{\text {air }}$ is the surface air pressure, $P_{o}$ the water pressure measured near the ADCP, $h_{2}$ the vertical distance between the pressure gauge and ADCP, and $\bar{\rho}$ the depth-averaged density between the ADCP and the surface/ice bottom. Values of $P_{\text {air }}$ should be obtained from local measurements if available; if not, from the more accurate of regional measurements, weather forecast models, or meteorological reanalysis products (e.g. Marshall, 2002). Here $P_{\text {air }}$ was measured at the nearby AWS. Ideally, the ocean pressure gauge should be co-located with the ADCP; in our case, the pressure gauge was deployed $139 \mathrm{~m}$ below the ADCP. The mean density $\bar{\rho}$ was calculated from CTD casts taken at mooring deployment and recovery and C3 moored temperature and salinity time series data. Substituting eqn. 2 into eqn. 1, we have an expression for the ice draft:

$$
h_{i c e}=\frac{P_{o}-P_{\text {air }}}{\bar{\rho} g}-h_{2}-h_{1}
$$

The cumulative time-dependent uncertainty in $h_{o}$ is approximately $\pm 0.17 \mathrm{~m}$ (based on independent uncertainties in $P_{o}$ (due to temperature sensitivity and mooring tilt), $P_{\text {air }}$, and $\bar{\rho}$. The mean uncertainty in $h_{2}$ is roughly $\pm 0.10 \mathrm{~m}$ based on accurate measurements of the mooring components and estimates of mooring stretch. The last term $h_{l}$ is computed using the acoustic range estimates from the $\mathrm{ADCP}$ along each beam to the underside of the ice, and thus requires careful consideration and a series of specific corrections.

The initial estimate of $h_{l}$ is obtained for each beam using the observed acoustic backscatter profile $B S(z)$. To obtain an estimate of $h_{1}$ with a resolution greater than the bin height, the centered first-difference of $B S$ at the midpoint $z_{i}$ between bins $i$ and $i+1$ is modeled using a slightly modified first-difference of a standard normal distribution:

$$
d \hat{B} S\left(z_{i}\right)=A\left[\frac{\left(-z_{i}+\mu\right)}{\sqrt{2 \pi} \sigma^{3}} \exp \left(\frac{\left(-z_{i}+\mu\right)^{2}}{2 \sigma^{2}}\right)\right]+C
$$

This functional form includes a constant multiplier $A$ and added constant $C$ to improve the fit with data, with $A$ and $C$ having units of $B S m^{2}$ and $B S$ and $\sigma, \mu$ and $z_{i}$ having units of meters. Values for $A, C, \sigma$ and $\mu$ are obtained by a non-linear least-squares fit to the observed 
$d B S(z)$ values in the three bins above and below the bin with maximum backscatter, yielding a total of six (first-difference) independent estimates of the slope of $d B S(z)$ and two degrees of freedom for the fit. The zero-crossing of $d \hat{B} S$, defined as $d \hat{B} S\left(\hat{z}_{o}\right)=0$, is the peak of the fitted backscatter profile, which is taken as the ice-water or air-water interface (Visbeck and Fischer, 1995).

We believe that this function (eqn. 4) improves upon the second-order polynomial fit used by Visbeck and Fischer (1995) since it gives a range to the surface which achieves a better match to the hydrostatic-based range $h_{o}$ and its tidal variability during times of open water (described later in section 4.6). Shcherbina et al. (2005) also found good results using a slightly different version of the normal distribution (his eqn. 9).

A set of corrections to these initial estimates are made next. These corrections take into account changes that would not greatly affect the current velocity profile and are therefore not included in standard ADCP processing, but are of the order of the signal when ice draft is estimated. Since the corrections are multiplicative, they become more important as the depth of the ADCP increases. These corrections for sound speed and instrument tilt are described in detail in separate sections below. After making these corrections, bad data are removed and a footprint error correction is made.

Finally, a best estimate for vertical range $\overline{\hat{z}}_{o}$ is made from the four individual beam estimates by averaging the two most similar corrected estimates $\frac{1}{2}\left(\hat{z}_{o 1}+\hat{z}_{o 2}\right)$.

\subsection{Sound Speed Correction}

A site-specific method for estimating the sound speed profile is required to accurately convert the round-trip acoustic travel time to range (Strass, 1998). Standard RDI ADCP processing uses a depth-independent sound speed profile computed from the ADCP temperature measurement and a constant salinity specified by the user, since sound speed variation is much more sensitive to changes in temperature than salinity (RDI-Primer, 1996). The multiplicative factor to correct for the difference between the true and ADCP specified sound speed profile is

$$
\varepsilon=\frac{C_{A D C P}}{C_{\text {real }}}
$$

where $C_{A D C P}$ is the ADCP-set sound speed and $C_{\text {real }}$ is the harmonic mean of the true sound speed profile. In most cases, time series of the true sound speed profile are unavailable. In fact, 
deep-keeled icebergs often occur in regions of sea ice, jeopardizing any attempts at upper water column density measurements. Therefore, one must use other information and a model of the evolving surface mixed layer (SML) to estimate the true sound speed profile (Strass, 1998). We use the UNESCO formulas for calculating sound speed and other sea water properties (Fofonoff and Millard, 1983).

The first correction uses salinity measured at a sensor very close (in this case, $9 \mathrm{~m}$ above) to the ADCP to replace the ADCP preset constant salinity. A second simple correction is to include the effect of pressure on the sound speed profile. This assumes, for lack of better information, the SML extends down to the ADCP, resulting in a constant potential temperature profile. Since sound speed depends on in situ temperature, the true sound speed will be greater and actual range will decrease. Fig. 4 shows the resulting corrections for a nominal range of $108 \mathrm{~m}$. Salt and pressure have a combined effect of about $0.05-0.10 \mathrm{~m}$ for most of the $\mathrm{C} 3$ time series.

The next correction is site-specific and requires a simple model of the upper layer hydrographic structure. We assume that the surface temperature is at the freezing point $T_{f}$ at the ambient surface salinity in the presence of sea ice. Using all available CTD profiles, one constructs a functional form to estimate the SML depth $h_{S M L}$ and the underlying temperature and salinity profile that can be empirically related to the temperature and salinity measurements on the mooring (Strass, 1998). The exact structure of the profile is not critical, but rather the harmonic mean of the resulting sound speed profile. This correction must also be applied to ULS sea ice draft estimates, so it is a general problem for ice draft estimates based on acoustic travel-time measurements.

In Marguerite Bay, the general features of the wintertime density profile are a SML with water very close to $T_{f}$ overlying a thermocline/halocline which warms towards the relatively warm and more saline Upper Circumpolar Deep Water (Smith et al., 1999). For this situation, we want to find the time-varying SML depth and then linearly interpolate from $T_{f}$ at $z=h_{S M L}$ down to the uppermost temperature and salinity measurements on the mooring. The base of the SML is usually associated with high rates of shear (Howard et al., 2004), so one could use the ADCP velocity data to determine $h_{S M L}$. We found the C3 ADCP current data too noisy to derive a reliable estimate of $h_{S M L}$ based on shear, and instead used the temperature and salinity measured at $99 \mathrm{~m}, 9 \mathrm{~m}$ above the ADCP. SML depths from 87 CTD stations made during the 2001 winter SO GLOBEC broad-scale hydrographic survey were examined and compared with the CTD 
temperatures at $99 \mathrm{~m}$. Linear regression analysis (Fig. 5) showed a roughly linear relationship between $h_{S M L}$ and temperature at $99 \mathrm{~m}$, with $R^{2}=0.59$. This linear fit was then applied to the $\mathrm{C} 3$ time series of temperature measured at $99 \mathrm{~m}$ to construct a time series of estimated $h_{S M L}$. We held the SML salinity constant at 33.95 psu based on the moored, broad-scale survey, and historical hydrographic data (Hofmann et al., 1996).

It should be noted that this method is applied to the entire year, while it is strictly only valid for winter stratification. During times of open water, there was often a surface layer of warm (above freezing) fresh melt water that can not be represented by the above empirical approach. Therefore, the zero ice draft estimates are more uncertain due to the inaccuracy of the sound speed correction method during times of extended open water. Application of the sound speed profile measured by CTD during the C3 mooring recovery on February 21, 2003, causes an overestimation of the ice draft by $0.31 \mathrm{~m}$, which reduces the estimated ice draft from $0.61 \mathrm{~m}$ to $0.30 \pm 0.40 \mathrm{~m}$, i.e., to zero draft within the uncertainty.

As seen in Fig. 4, these SML depth corrections have a larger effect than the salt and pressure corrections described above. The correction is as much as $0.50 \mathrm{~m}$ for May and June, when sea ice is forming. During September and parts of August and December, the SML extended below the ADCP, so no correction is necessary.

As a final check, we compared the modeled sound speed profile with that observed during the only winter-time CTD cast taken close $(9.3 \mathrm{~km})$ to $\mathrm{C} 3$ on August 26, 2002. As shown in Fig. 6, the salinity, temperature, and sound speed profiles match well. The overall range correction is nearly identical, with the modeled correction adding $0.199 \mathrm{~m}$ to $h_{l}$ and the sound speed correction using the observed profile adding $0.206 \mathrm{~m}$.

\subsection{Tilt Correction}

The backscatter profile must be corrected for instrument pitch and roll, since standard ADCP processing uses the instrument tilt to bin-map the velocity data but not backscatter data (RDIPrimer, 1996). Due to the beam geometry, this correction affects each beam differently, and inherently tends to collapse the separate estimates from each of the four beams towards one value. The multiplicative factor applied to the range estimate to correct for instrument tilt can be expressed as

$$
\frac{\cos \left(\theta \pm\left(\left(\theta_{p}(t)+\theta_{p}{ }^{\prime}\right),\left(\theta_{r}(t)+\theta_{r}{ }^{\prime}\right)\right)\right)}{\cos (\theta)}
$$


where $\theta$ is the ADCP beam angle (20 for the RDI Workhorse), and $\left(\theta_{r}, \theta_{p}\right)$ are the roll and pitch angles, with the \pm indicating that one should add or subtract depending on the sign convention dictated by the configuration of the sensors in the instrument. For an upward-looking RDI ADCP, one should add roll for beam 1, subtract roll for beam 2, add pitch for beam 3 and subtract pitch for beam 4 .

The standard tilt sensors on an RDI Workhorse ADCP have a resolution of $0.01^{\circ}$, yet have an accuracy and precision of only $\pm 0.5^{\circ}$. The latter represents about $0.32 \mathrm{~m}$ of uncertainty for every $100 \mathrm{~m}$ of instrument depth. To reduce this uncertainty, constant offsets $\left(\theta_{r}{ }^{\prime}, \theta_{p}{ }^{\prime}\right)$ are added to the roll and pitch time series. These values are chosen to minimize, in a least squares sense, the difference between the range estimate $h_{1}$ from the two beams affected by that axis of the tilt sensor for the entire time series. The range of acceptable values for $\left(\theta_{r}{ }^{\prime}, \theta_{p}{ }^{\prime}\right)$ is constrained by the accuracy and precision of the sensor. For $\mathrm{C} 3, \theta_{r}{ }^{\prime}=-0.27^{\circ}$ and $\theta_{p}{ }^{\prime}=0.04^{\circ}$, corresponding to $0.19 \mathrm{~m}$ and $0.03 \mathrm{~m}$ corrections, respectively, on a total nominal range of $108 \mathrm{~m}$.

\subsection{Removing Bad Data}

A series of criteria are applied to find erroneous data and remove them (Strass, 1998). Since many data sources contribute to the ice draft estimate, the first step involves acceptable range checking of any auxiliary data (temperature, salinity, air or water pressure). Next, data were eliminated for times when the ADCP ensemble averaging in space and time and the fitting function (eqn. 4) to the backscatter profile for a single ADCP beam failed to accurately determine the range to the surface. When the standard deviation of the residuals of the fitted function $\sigma_{\hat{z}_{o}}$ exceeded a chosen threshold, the range estimate was omitted. The threshold chosen here was $6.7 \mathrm{BSU}$, which eliminated about $10 \%$ of the values. There was no significant bias in the residuals.

Finally the difference between the estimates from the two most similar beams was examined. A maximum limit, $0.25 \mathrm{~m}$, for this difference excluded $8 \%$ of the remaining data. Overall, about $18 \%$ of the data was removed due to these combined tests.

\subsection{Footprint Error}

A footprint error is associated with the wide beam of the ADCP being backscattered from the deeper parts of the ice plus shadowing due to the nominal $20^{\circ}$ beam angle (Vinje et al., 1998). This error is defined as the difference between the measured draft and the mean ice draft and is a 
function of the instrument depth. The average surface diameter of an individual beam is $3.9 \mathrm{~m}$ for the C3 ADCP, which gives a footprint error of $0.4 \mathrm{~m}$ (see Fig. 8 in Vinje et al, 1998), which has been subtracted from the measured ice draft to get the expected mean draft shown in Fig. 8 . For lack of other information, we have assumed here that the underwater roughness of ice in Marguerite Bay resembles Arctic winter ice for estimate the footprint error. See Vinje et al. (1998) for detailed discussion of the causes and estimation of footprint error.

\subsection{Uncertainty Estimate}

The uncertainty in the range estimate for each ensemble can be divided into that due to the empirical fitting function (eqn. 4) and that due to the sound speed correction. First, we describe each separately here, since the former is specific to the ADCP and the latter is universal to all acoustic ice draft estimates. Then we discuss the combined uncertainty.

\subsubsection{Uncertainty Due to the Empirical Fitting Function}

Estimation of the error in the ice draft estimate is complicated because the range is obtained from a non-linear fitting procedure for $\hat{z}_{o}$. Therefore, we performed a Monte Carlo simulation of the range estimate $\hat{z}_{{ }_{O M C}}$ obtained using eqn. 4 in order to estimate range uncertainties due to random errors in the backscatter intensity. The median values for the one-year time series of the coefficients in eqn. 4 ( $A=-1450 \mathrm{BSU}, C=-1 \mathrm{BSU}, \sigma=2.8 \mathrm{~m}$, and $\mu=107.5 \mathrm{~m}$ ) were used to calculate a median range and six-point synthetic profile. Normally distributed random noise was then added to each $d B S$ point in the synthetic profile to test the sensitivity of the range estimate to noise in the backscatter profile. The synthetic noise had zero mean and a standard deviation $\sigma_{n}$ which we varied from 0 to $10 \mathrm{BSU}$. For each value of $\sigma_{n}$, the mean of $\hat{z}_{o M C}$ was indistinguishable from that of the median value profile. A Kolmogorov-Smirnov test confirmed that $\hat{z}_{o}$ in the Monte Carlo simulation had a normal distribution.

The standard deviation of $\hat{z}_{o M C}, \sigma_{\hat{z}_{o M C}}$, was calculated as a function of $\sigma_{n}$ and shown in Fig. 7. $\sigma_{\hat{z}_{o M C}}$ increases linearly with $\sigma_{n}\left(\sigma_{\bar{z}_{o M C}}=0.031 \sigma_{n}-0.0019, R^{2}=0.99\right)$. We then applied this relationship to each of the two most similar beams $\sigma_{\hat{z}_{o 1}}, \sigma_{\hat{z}_{o 2}}$ and estimated the total uncertainty in

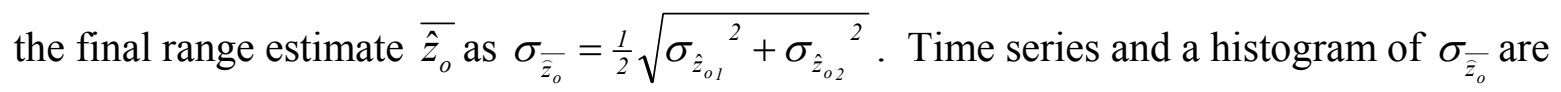
shown in Fig. 8. The peak in the distribution at $0.065 \mathrm{~m}$ gives an estimate of the most likely uncertainty due to the empirical fitting in our C3 example. The upper bound on uncertainty lies 
at a $\sigma_{{\overline{\bar{z}_{o}}}_{\mathrm{o}}}$ of about $0.15 \mathrm{~m}$. This appears to be relatively constant during the one-year time series.

\subsubsection{Uncertainty in the Sound Speed Correction}

The range correction due to sound speed carries an uncertainty associated with the modeling of the sound speed profile. In our example, this depends on the uncertainty in the estimate of the SML depth. To quantify this, we rewrite eqn. 5 as

$$
\varepsilon=\frac{C_{A D C P}}{C_{\text {real }}} \pm \frac{C_{A D C P}}{C_{\text {real }}} \frac{\sigma_{C_{\text {real }}}}{C_{\text {real }}}
$$

where the second term quantifies the uncertainty in the first term. To calculate $\sigma_{C_{\text {real }}}$, we added and subtracted the standard deviation $\sigma_{S M L}=21.8 \mathrm{~m}$ of the misfit in the linear regression shown in Fig. 5 to the estimated SML depth for each ensemble. We used these upper and lower bounds and the method in section 4.1 to calculate bounds on $C_{\text {real }}$, the difference being $\sigma_{C_{\text {real }}}$. A time series and histogram of the resulting uncertainty in the range $108 \cdot C_{A D C P} \sigma_{C_{\text {real }}} / C_{\text {real }}^{2}$ is shown in Fig. 8. The time series shows the uncertainty to be about $0.15 \mathrm{~m}$ from April to July when the SML is well above the ADCP, and about $0.025 \mathrm{~m}$ from August to February (except November) when the SML extends down to the ADCP and is thus well-resolved. These two periods correspond to the two peaks in the histogram. The upper bound on uncertainty due to the sound speed correction is $0.18 \mathrm{~m}$.

\subsubsection{Combined Uncertainty}

The combined uncertainty due to the empirical fitting function and the sound speed correction can be expressed as

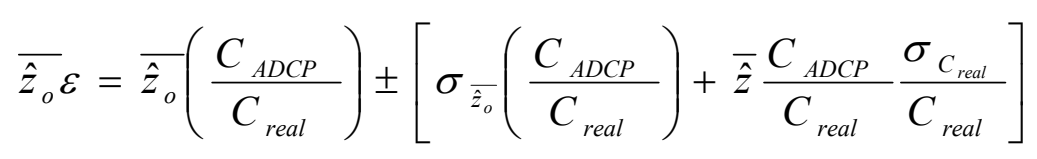

where the first term on the right side is the best estimate of the range and the second term in brackets is the total uncertainty. The time series and histogram (Fig. 8) show that during periods of low uncertainty in the sound speed correction (i.e., deep SML), the uncertainty associated with the empirical fitting dominates giving a combined uncertainty of about $0.10 \mathrm{~m}( \pm 0.20 \mathrm{~m} \mathrm{95 \%}$ confidence interval). In April to July, the sound speed correction uncertainty exceeds that associated with the empirical fitting, increasing the combined uncertainty to around $0.22 \mathrm{~m}$

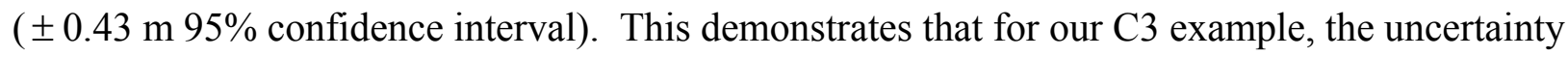


in the sound speed profile is of the same importance as that of the acoustic ranging for ice draft estimation.

\subsection{Example Results from Marguerite Bay}

To test this method, range estimates at high frequencies were examined. The surface tidal amplitude in central Marguerite Bay is about 1-2 m, which is of the same order as the ice draft and smaller than the C3 ADCP bin size. In principle, the surface tidal signal should be captured in both the ocean pressure record $P_{o}$ and the ADCP acoustic range estimate $h_{l}$ so that the effect of the surface tide should be removed when eqn. 3 is evaluated. We found the method is accurate enough to produce a time series of $h_{1}$ with a consistent surface tidal signal even when the surface remains in one ADCP bin for nearly the entire year. Fig. 9 shows $h_{1}$ and the hydrostatic range $h_{o}$ (eqn. 2) for a 10-day period of open water in April, 2002. The average difference between the two time series is $0.15 \mathrm{~m}$. The average of the absolute value of the difference is $0.18 \mathrm{~m}$, with $95 \%$ of those values less than $0.40 \mathrm{~m}$.

Two phenomena are responsible for non-zero ice draft estimates during times of open water. First, ambiguity of the sound speed profile prevents a truly accurate range estimate during the spring melt, around December and January in Marguerite Bay, when a fresh mixed layer with temperatures well above freezing forms which is unresolved by our sound speed correction method. Second, it is unclear how the ADCP ensemble averaging resolves the surface waves during times of open water. The acoustic return from wave troughs versus peaks may not be identical and could introduce some bias. Furthermore, air bubbles entrained during wave breaking may affect the acoustic return. Because these errors are based on sea state, they are difficult to correct. However, as shown in Fig. 9, the method works well in the fall when the spring melt layer is absent.

The final ice draft time series is shown in Fig. 10 (upper panel). The maximum drafts were quite large, with extended periods of average daily values of 2 to $4 \mathrm{~m}$ in August and September, 2002. This period of thick ice ended abruptly, but ice was still present until January as seen in Fig. 3. This early arrival of multi-meter-thick ice in Marguerite Bay in 2002 was observed by the R.V.I.B. Nathaniel B. Palmer when she was trapped in the ice for several days during this period. The indication of $0.5-1.0 \mathrm{~m}$ thick ice in February 2003 is most likely due to a poor estimate of the sound speed profile as a result of an unresolved surface melt layer. It is worth noting that a warm surface layer increases sound speed, which causes the ADCP range to the 
surface to decrease and apparent ice draft to increase, making this explanation of the error physically consistent. Accurate ice draft estimates in springtime should be possible provided that the mixed layer temperatures are measured. Furthermore, one could potentially use short windows of open water to improve the uncertainty in the sound speed estimate during this period.

The time series of ice draft allows computation of the monthly ice draft distribution shown in Fig. 10 (lower panel). The distribution is binned in 1-m bins and shows the initial condition of nearly ice-free waters which freeze up in fall and by September 2002 have 36\% 2-3 $\mathrm{m}$ ice and $27 \%$ 3-4 m ice. In August 2002, 10\% of the ice draft exceeds $5.0 \mathrm{~m}$. Ice velocities can be estimated from the ADCP bin used above to determine the ice thickness and combined with ice thickness estimates to examine the ice momentum balance for this region.

\subsection{ADCP Averaging}

The inherent ADCP temporal/spatial averaging also affects ice draft estimation. Fig. 11 shows a transect of ice draft and thickness measured by drilling through the ice every $2 \mathrm{~m}$ along a 100-m linear grid at an ice camp $9 \mathrm{~km}$ from the C3 mooring site during August 2001 (Perovich et al., 2004). This transect clearly illustrates the great variability in ice draft on very short horizontal scales. The ADCP ensemble averaging in time results in further spatial averaging as the ice moves beyond the area averaged by the combination of the data from the four beams into a single estimate of draft for each observation. Thus, since the ADCP-based estimates are an areal average, they can not resolve the short spatial variability found in Marguerite Bay. An ULS or similar vertical narrow-beam sonar is needed to sample this small-scale variability. For an ULS moored at $108 \mathrm{~m}$, its beam width at the sea surface would be $3.4 \mathrm{~m}\left(1.8^{\circ}\right.$ spread vertical beam).

\section{Recommendations for Future Deployments}

The following steps could improve the ice draft estimates made with a moored upwardlooking ADCP. First, $P_{o}$ should be measured using a high precision pressure gauge mounted on or very close to the ADCP. This would minimize $h_{2}$ and its uncertainty and improve the estimation of the ADCP depth $h_{o}$ and any variability due to mooring motion. Second, using locally measured $P_{\text {air }}$ reduces uncertainty introduced by using distant observations or atmospheric reanalysis products. Third, a measurement plan for accurate sound speed profile 
estimation will greatly reduce the error and uncertainty in both ADCP and ULS estimates of ice draft. Fourth, the shallower the ADCP is deployed, the more accurate the ice draft estimate will be due to decreased geometric errors and smaller errors in the extrapolation of sound speed. However, ADCPs are usually deployed to provide velocity profiles over a significant depth range. Since sound speed depends more on temperature than salinity in polar waters, a simple thermistor chain or a winched CTD system such as the WHOI Arctic Winch (Straneo and Saucier, 2007; Pickart, 2007) could provide an improved sound speed correction. The latter can provide coverage throughout the upper water column and also avoid damage due to deep ice keels or ice bergs. An improved tilt sensor in the ADCP would also avoid the need for the constant tilt offsets $\left(\theta_{r}{ }^{\prime}, \theta_{p}{ }^{\prime}\right)$ as described in section 4.2.

\section{Conclusions}

We describe here a technique to estimate ice coverage, draft and velocity using data from a subsurface moored upward-looking acoustic Doppler current profiler (ADCP) deployed in Marguerite Bay on the western Antarctic Peninsula as part of the Southern Ocean GLOBEC program. We found that ADCP windowed variances of vertical velocity and error velocity and surface horizontal speed provide good indicators of the presence of ice at this site, but not ADCP surface signal correlation and backscatter intensity. Thus ice coverage can be estimated independent of local satellite data.

Ice draft estimation requires corrections to the range from the ADCP to the underneath surface of the ice for instrument depth, tilt and sound speed profile. The depth of the ADCP is estimated using a combination of the mooring configuration, local atmospheric surface pressure and moored pressure data, and hydrostatics. The instrument tilt correction is greatly improved by a constant offset which minimizes the difference between individual beam range estimates. This offset introduced a $0.03 \mathrm{~m}$ and $0.19 \mathrm{~m}$ correction to pitch and roll, respectively. The sound speed correction introduced an offset of between about 0 and $0.55 \mathrm{~m}$, with an average magnitude of about $0.30 \mathrm{~m}$.

We used two separate ways to calculate the uncertainty in the ice draft estimate. First, the range estimate during times of open water resolves the surface tides to within $\pm 0.32 \mathrm{~m} 95 \%$ of the time. Second, a Monte Carlo simulation determines the sensitivity of the zero-crossing of the backscatter profile fitting function (eqn. 4) to backscatter noise. The most likely uncertainty associated with the empirical fitting function is $\pm 0.13 \mathrm{~m}$ ( $95 \%$ confidence interval). The 
uncertainty associated with the sound speed correction had two regimes. One regime occurred during midwinter when the surface mixed layer extended down to the ADCP and the sound speed correction was nearly zero with a small uncertainty, about $\pm 0.025 \mathrm{~m}$. The other regime carries a larger uncertainty, about $\pm 0.15 \mathrm{~m}$, due to the ambiguity in the location of the surface mixed layer depth. We calculated a most likely total combined uncertainty of $\pm 0.10 \mathrm{~m}(95 \%$ confidence interval) during midwinter and $\pm 0.43 \mathrm{~m}$ (95\% confidence interval) when we had less confidence in our assessment of the surface mixed layer depth.

The two independent estimates of uncertainty during times of open water $( \pm 0.32$ and \pm 0.43 $\mathrm{m})$ are consistent and suggest an uncertainty of about $\pm 0.40 \mathrm{~m}$ in the estimate of ice draft at this site, or about $0.4 \%$ of the nominal range of the ADCP. This is larger than that reported for an optimized ice draft estimate $(0.04 \mathrm{~m})$ using a ULS deployed at a nominal depth of $150 \mathrm{~m}$ in the Weddell Sea (Strass, 1998), or $0.026 \%$ of the nominal depth. In other words, on a percentage basis, the ULS has significantly less uncertainty than the ADCP. The uncertainty in both cases depends highly upon the modeling of the sound speed profile.

Our study indicates that the ADCP is not a substitute for a dedicated ULS for detailed ice draft measurements, but it does give additional information about both ice and ocean velocities. An $\mathrm{ADCP}$ is more than adequate to observe the onset and breakup of sea ice and can provide valuable estimates of ice draft and velocity with little extra effort. The ideal configuration is a combination of ADCP and ULS deployed on the same mooring with separate instrumentation to determine the sound speed profile.

Acknowledgements: The AWS stations and data acquisition and initial processing were provided by the University of Wisconsin Antarctic Meteorological Research Center with the support and help of M. Lazzara. Thanks to the captains and crews of the A.R.S.V. L.M. Gould and R.V.I.B. N.B. Palmer, R. Limeburner and the WHOI Subsurface Mooring Operations Group led by S. Worrilow, and the Raytheon Polar Services support crew responsible for collecting the moored array and AWS data. Thanks to D. Perovich for the ice camp data, discussions and Figure 11. This work benefited from conversations with A.Y. Shcherbina and thorough reviews by V. Strass and an anonymous reviewer. This work was supported by the NSF Office of Polar Programs through U.S. Southern Ocean GLOBEC grants OPP 99-10092 and OPP 06-23223, the WHOI Smith Chair in Coastal Oceanography, and the WHOI Education Office. This is U.S. GLOBEC 
contribution number 566 .

\section{References}

Belliveau, D., G. Bugden, B. Eid and C. Calnan, 1990. Sea ice velocity measurements by upward-looking Doppler current profilers. J. Atmos. Oceanic Technol., 7, 596-602.

Bolmer, S.T., this issue, A note on the development of the bathymetry of the continental margin west of the Antarctic Peninsula from $65^{\circ}$ to $71^{\circ} \mathrm{S}$ and $65^{\circ}$ to $78^{\circ} \mathrm{W}$.

Cavalieri, D., P. Gloerson, and J. Zwally, 1990, updated 2005. DMSP SSM/I daily polar gridded sea ice concentrations, January 2001 to December 2003. Edited by J. Maslanik and J. Stroeve. Boulder, CO: National Snow and Ice Data Center. Digital media.

Comiso, J., 1999, updated 2005. Bootstrap sea ice concentrations for NIMBUS-7 SMMR and DMSP SSM/I, January 2001 to December 2003. Edited by J. Maslanik and J. Stroeve. Boulder, CO: National Snow and Ice Data Center. Digital media.

Fofonoff, N., and R.J. Millard, 1983. Algorithms for computation of fundamental properties of seawater. UNESCO Technical Papers in Marine Science, 44, 53 pp.

Fukamachi, Y., G. Mizuta, K.I. Ohshima, H. Melling, D. Fissel, and M. Wakatsuchi, 2003. Variability of sea-ice draft off Hokkaido in the Sea of Okhotsk revealed by a moored iceprofiling sonar in winter of 1999. Geophysical Research Letters, 30(7), 1376, doi:10.1029/2002GL016197, 2003

Hofmann, E.E., J.M. Klinck, C.M. Lascara and D.A. Smith, 1996. Water mass distribution and circulation west of the Antarctic Peninsula and including Bransfield Strait. Antarctic Research Series, Foundations for Ecological Research West of the Antarctic Peninsula, 70, 61-80.

Hofmann, E.E., P.H. Wiebe, D.P. Costa and J.J. Torres, 2004. An Overview of the Southern Ocean Global Ocean Ecosystems Dynamics Program, Deep-Sea Research II, 51, 1921-1924.

Howard, S.L., J. Hyatt and L. Padman, 2004. Mixing in the pycnocline over the Western Antarctic Peninsula shelf during Southern Ocean GLOBEC. Deep-Sea Res. II, 51(17-19), 1965-1980.

Hudson, R., 1990. Annual measurements of sea-ice thickness using an upward-looking sonar. Nature, 344, 135-137.

Marshall, G., 2002. Trends in Antarctic Geopotential Height and Temperature: A comparison between Radisonde and NCEP-NCAR Reanalysis data. J. Climate, 15, 659-674. 
Melling, H., P.H. Johnston and D.A. Riedel, 1995. Measurements of the underside topography of sea-ice by moored subsea sonar. J. Atmos. Oceanic Technol., 12, 589-602.

Moffat, C., R.C. Beardsley, R. Limeburner, B. Owens, M. Caruso, and J. Hyatt, 2005. Southern Ocean GLOBEC Moored Array and Automated Weather Station Data Report. Woods Hole Oceanog. Inst. Tech. Rept., WHOI-2005-07, pp. 133.

Perovich, D.K., B.C. Elder, K.J. Claffey, S. Stammerjohn, R. Smith, H.R. Krouse, A.J. Gow and S.F. Ackley, 2004. Winter sea ice properties in Marguerite Bay, Antarctica. Deep-Sea Res. II, 51(17-19), 2023-2040.

Pickart, R., 2007. Reaching Up Into Perilous, Icy Waters. Oceanus, http://www.whoi.edu/oceanus/viewArticle.do?id=19787

RDI-Primer, 1996. Acoustic Doppler current profiler principles of operation: A Practical Primer. Tech. rep., RD Instruments, San Diego, CA.

Shcherbina, A.Y., D.L. Rudnick, and L.D. Talley, 2005. Ice-draft profiling from bottommounted ADCP data. J. Atmos. Oceanic Technol., 22, 1249-1266.

Smith, D.A., E.E. Hofmann, J.M. Klinck and C.M. Lascara, 1999. Hydrography and circulation of the West Antarctic Peninsula continental shelf. Deep-Sea Res. II, 46, 925-949.

Strass, V., 1998. Measuring sea ice draft and coverage with moored upward looking sonars, Deep-Sea Res., 45, 795.

Straneo, F. and F. Saucier, 2007. The outflow from Hudson Strait into the Labrador Sea. Deep Sea Res., (in revision).

Vinje, T., N. Nordlund, and A. Kvambekk, 1998. Monitoring ice thickness in the Fram Strait. $J$. Geophys. Res., 103(C5), 10,437-10,449.

Visbeck, M., and J. Fischer, 1995. Sea surface conditions remotely sensed by upward-looking ADCPs. J. Atmos. Oceanic Technol., 12, 141-149. 